\title{
Experiência Religiosa e Experiência Estética em Artistas Plásticos: Perspectivas da Psicologia da Religião
}

\author{
Geraldo José de Paiva' \\ Agnaldo Garcia \\ Andréa K. Gonçalves \\ Cristiana T. Scala \\ David G. R. de Faria \\ M. Luisa Trovato Gómez. \\ Marina P. Jordão \\ Rute C. Barbosa \\ Suely M. S. Franca \\ Universidade de São Paulo
}

\begin{abstract}
Resumo
Pode a experiência religiosa ser substituída pela experiência estética? Os estudiosos se dividem na resposta. Situando a pergunta no quadro de referência conceitual e epistemológico que distingue entre religião substantiva e religião funcional, levantamos a hipótese de que não há substituição substantiva, mas pode haver substituição funcional entre essas experiências. Levantamos a hipótese ulterior de que a experiência estética pode ser uma experiência do sagrado. As hipóteses foram examinadas com os dados obtidos em entrevistas com oito renomados artistas plásticos, por ocasião da $23^{a}$ Bienal de São Paulo, em 1996. Os dados revelaram diferenças, continuidades e analogias entre arte e religião assim como entre arte e sagrado, que permitiram reconhecer em alguns casos substituição funcional da religião pela arte, principalmente se dotada da densidade do sagrado.

Palavras-chave: Estética, experiência religiosa, psicologia da religião, sagrado.
\end{abstract}

Religious Experience and Aesthetic Experience in Plastic Artists: Perspectives from the Psychology of Religion

\begin{abstract}
Can aesthetic experience replace religious experience? Researchers are quite divided about this issue. From a conceptual and epistemological framework that distinguishes between substantive and functional religion, we formulated the hypothesis that there is not a substantive replacement, but there can be a functional replacement of religious experience by an aesthetic experience. We also considered the additional hypothesis that aesthetic experience can be an experience of the sacred. The hypotheses were examined with the help of interviews with eight well known Brazilian artists, by the time of the 23rd Biennial International Exhibition of Arts of São Paulo, 1996. The data revealed differences, continuities, and analogies between art and religion and between art and the sacred, that allowed to identify in some cases a functional replacement of religion by art, especially if art was endowed with the density of the sacred.

Keywords: Aesthetics; psychology of religion; religious experience; the sacred.
\end{abstract}

Experiência religiosa e experiência estética são complexos processos psicológicos que envolvem os sentidos, a cognição e o afeto e dizem respeito à imediata apreensão respectivamente do objeto religioso e do objeto belo, em particular na obra de arte. Tem-se discutido se, especialmente entre as pessoas cultas, a experiência religiosa pode ser substituída pela experiência estética. Goethe, porta-voz dessa substituição, acolhida por Freud (1930/1978, p. 38), afirma, com efeito: "quem tem arte e ciência, esse tem religião; quem não as tem, esse tenha religião". A produção e recepção da obra de arte por envolver, passageiramente embora, a pessoa inteira, sentidos, cognições, emoções, é capaz de arrebatá-la, colocá-la em êxtase, isto é, fora de si, menos possuidora da

\footnotetext{
${ }^{1}$ Endereço para correspondência: Av. Professor Mello Moraes, 1721, 05508900 , São Paulo, SP.E-mail: gjdpaiva@usp.br
}

obra do que possuída por ela, tal como se diz da experiência religiosa intensa. Pode-se, pois, perguntar se a experiência da arte pode fazer às vezes da experiência religiosa.

Estudiosos de múltiplas áreas parecem apontar certa convergência ou equivalência entre as duas experiências. Régamey, fundador da revista L'Art Sacré e renovador da arte sacra católica, é do parecer de que toda obra de arte válida tem o caráter de sagrado (Montrond, 1996, p. 665). Na mesma linha vai Coomaraswamy, curador do Museu de Belas Artes de Boston, especialista em arte sacra hinduísta e budista (Whaling, 1985). Lommel (citado em Berlyne,1980, p. 360) dá a uma de suas obras o título "o xamanismo é o começo da arte". Charru (1996, p. 96), discutindo a "teologia sonora" do compositor. Messiaen, cita o juízo de um autor para quem a música desse compositor "faz entrar em contato com a 
própria substância dos mistérios". Comparando o barroco com a arte de Malevitch e Mondrian e, em geral, com a arte moderna, Court (1989, p. 56) vê a diferença entre essas formas de arte na procura do absoluto ou por meio da forma perfeitamente purificada dos modernos, ou pelo uso "do duplo movimento poderosamente articulado de rebaixamento e de elevação infinita" do barroco. Baillache (1993), além de citar em exergo a Kafka, "escrever, forma de oração" (1993, p. 231), afirma que a arte é a possibilidade de religião dos ateus. O teólogo Tillich modificou o título de suas conferências sobre Arte e Religião para Arte e Realidade Última, entendendo que tanto a religião como a verdadeira arte buscam a realidade definitiva (Arnheim, 1987). Ainda no nível da teologia, a Estética Teológica de von Balthasar (Fisichella, 1994), articulada a partir do pulchrum, confirmaria a sensibilidade estética como coincidente, ao menos em parte, com a sensibilidade religiosa.

Lugar de destaque na aproximação da arte com a religião deve ser dado à obra $O$ Sagrado, do filólogo e teólogo alemão Rudolf Otto (1917/1936). Otto considera distintivos da religião seus aspectos supra-racionais, não captados nem mesmo pelos conceitos superlativos. Mas ensina que esses aspectos devem ser evocados por um tipo de sensibilidade estética: o mysterium tremendum et fascinans é discernido pela "adivinhação" (divinatio; 1936, p.147ss.) nos sons, nas luzes, na escuridão ou no silêncio e nas várias formas de arte.

Outros estudiosos, porém, são de opinião de que arte e religião não têm muito a ver uma com a outra. Weber (1982, p.171), por exemplo, além de observar que o sagrado pode ser precisamente o não-belo, afirma que "o campo da arte [é talvez] um campo de grandiosidade diabólica, ... em sua essência hostil a Deus e à fraternidade humana". Charru (1996, p. 97) concorda com Stravinsky em que a música não é a "arte/religião" wagneriana e acrescenta que a obra de Messiaen exige um juízo de discernimento espiritual quando pretende a apreensão imediata dos mistérios "sem passar pela noite, sem resistência sofrida, sem espera, numa imediação sem surpresa”. O filósofo Rehfeld (1981) distingue religião e arte, mostrando que a religião realiza a integração dos sentimentos de modo superior. L. Dupré, filósofo da religião (1981, p. 28), discutindo religião na era secular, adverte: "abolir a distinção (entre o finito e o infinito) resulta num panteísmo estético, incompatível com a transcendência tão essencial a qualquer religião genuína". Finalmente, de Certeau (1996, p. 147) pensa que há épocas em que "do ato religioso concreto subsiste a forma ética e estética, ao passo que o seu conteúdo dogmático desaparece".

$\mathrm{Na}$ área da Psicologia encontramos a mesma duplicidade de pontos de vista. Berlyne (1980), no capítulo de Estética Psicológica no Handbook of Cross-Cultural Psychology, admite proximidade ou, mesmo, equivalência entre algumas percepções estéticas e algumas percepções religiosas quando escreve: "O que os ocidentais reconhecem como produções artísticas de outra cultura são freqüentemente representações de rituais mágico-religiosos ou objetos criados para o uso nesses rituais" (1980, p. 328). Allport (1950; 1966), que se interessava pelos temas da personalidade e da religião individual, ao operacionalizar os "tipos ideais" de Spranger (Allport, Vernon \& Lindzey, 1960), reconhecia a distinção entre o tipo estético e o tipo religioso, aquele sensível à harmonia das partes, este à integridade do todo, e a fácil transição pessoal do estético para o religioso.

De outro lado, Watts e Williams (1988, p. 140), embora apreciem várias analogias entre a cognição religiosa e a cognição estética, não gostariam de ver a "religião degenerar em estética". Mais sobriamente, Krech e Crutchfield (1971) fazem notar que os sentimentos estéticos e os sentimentos religiosos são emoções distintas em razão das qualidades fisionômicas dos objetos que os provocam: beleza, fealdade, acabamento nos primeiros, grandiosidade e mistério nos segundos.

Uma posição mista é apresentada pelo grande teórico e pesquisador de psicologia da arte Rudolf Arnheim. Discutindo a experiência estética e a experiência religiosa, Arnheim (1987) insiste na importância da primeira para a segunda, enquanto o conteúdo espiritual da religião é corporificado, ou seja, trazido à condição da existência física, pela arte. Para a pessoa religiosa, diz Arnheim, não basta aceitar, por exemplo, a existência de Deus: "é preciso que (essa existência) seja sentida reverberando na própria mente do fiel, de modo que quando, no Livro de Jó, Deus responde do meio do redemoinho, o leitor seja esmagado pela grandeza da criação" (1987, p. 50). Arnheim traz à discussão as relações entre arte religiosa e realidade, as várias espécies de verdade estética (icônica, histórica e universal), o tema ou assunto religioso. Quanto a esse, pergunta se um artista sem fé pode produzir um objeto de arte religiosa, capaz de despertar emoção estético-religiosa. A pergunta se justifica pelo caso famoso da igreja de Nossa Senhora das Graças em Assy, França, cuja decoração foi confiada pelos dominicanos a pintores e escultores de prestígio, reconhecidamente ateus, comunistas ou não-cristãos (Montrond, 1996). Segundo Arnheim, "parece seguro supor que o tema religioso ao qual os artistas se aplicaram, o Apocalipse, a Crucifixão, a Virgem da ladainha, exerceu sobre eles o poder evocativo inerente a qualquer grande tema, de qualquer origem. $\mathrm{O}$ impacto das dimensões universalmente humanas do tema sobre os artistas pode dar conta da eficácia mais especificamente religiosa de suas contribuições" (1987, p. 49). Ampliando o horizonte para além da obra de arte, pergunta-se Arnheim se uma imagem visual pode ser alguma 
vez denominada religiosa quando lhe falta o tema tradicional de qualquer credo particular. É o caso da representação da Natureza. Segundo o autor, a paisagem soberba, ao mostrar "poder, abundância inexaurível, variedade, ordem, engenhosidade e mistério", só fala dela mesma: "a fé pode ser trazida às imagens como uma interpretação, mas não é pronunciada pelas imagens mesmas" (Arnheim, 1987, p. 50). Também a obra de arte não-figurativa, na qual a abstração atinge o máximo, reluta em exprimir a realidade última, por causa do distanciamento da experiência concreta. Mas, afinal, experiência estética e experiência religiosa são diferentes? Arnheim responde que há muito de semelhante entre ambas, pois a religião leva à veneração "da natureza do mundo no qual se nasceu" e à conformidade de vida com as exigências reveladas por aquela experiência. Coisa parecida acontece com a arte: "a criação artística é a maneira de o artista colocar o trabalho de uma vida no contexto do mundo de que tem experiência". E cita, para destacar a afinidade entre religião e arte, a definição da atividade do artista como "celebração através do louvor" (p. 51). Tampouco a recepção da obra de arte é passiva: “o espectador sente-se impelido a viver no grau de intensidade, pureza e sabedoria nela refletidas" (p. 51). Em artigo de cunho filosófico, Arnheim (1991) lamenta a "dupla verdade" da ciência e da religião, cisão que acarreta dificuldades psicológicas, e advoga a capacidade que têm as artes plásticas, a arquitetura, a dança, a literatura e a música de servir à religião secular, como já serviram às religiões históricas, enquanto corporificam o sentimento oceânico, origem imaginária dos deuses. As artes e a literatura "alcançam sua verdadeira validade apenas quando exibem o tipo de transparência pelo qual as aparências perceptíveis de nosso mundo são reveladas como metáforas daquilo que pode ser experimentado como a natureza de nossa vida" (p. 7). Como no estudo precedente, o autor conclui que quanto mais se avança além dos aspectos acidentais da religião e da arte, menos evidente se torna a diferença entre elas. "Eu disse da religião que ela começa onde o conhecimento factual se eleva em temor, confiança e louvor. $\mathrm{O}$ mesmo vale para a arte". Mas ressalva imediatamente: "talvez o máximo que se possa dizer é que as artes são apenas uma das fontes que geram a religião, mas que comprovaram ser seu meio geral mais efetivo" (p. 8).

Entre os psicólogos da religião, P. W. Pruyser (1968) procura relacionar sistematicamente religião e arte. Como Presidente da Society for the Scientific Study of Religion propôs algumas "Lições da Teoria da Arte para a Psicologia da Religião" (Pruyser, 1976). Segundo Pruyser, a pessoa tende a ser introduzida ao mesmo tempo na religião e na arte, de modo que, desde a infância, ambas se reforçam mutuamente. Os constructos da teoria da arte, habilidade, imaginação e ilusão, aplicam-se, com proveito, ao entendimento da religião. A habilidade, por exemplo, é adquirida nos exercícios religiosos, com destaque da prática ritual. A imaginação e a fantasia permitem "brincar" com a realidade, libertando-a da constricção do concreto e conferindo-lhe novos modos de ser. A ilusão, finalmente, aponta o "peculiar estado ontológico dos objetos de arte, a meio-caminho entre a mente e a matéria"(p. 7). Sob esse aspecto, a arte é irredutível a qualquer perspectiva que não a da própria arte, embora as ciências, desde a física até a psicologia social, tenham algo a dizer acerca de alguns aspectos da arte. Nesse ponto, o autor se reencontra com Winnicott e com Freud, no sentido de que a religião é ilusão, isto é, ocupa o espaço transicional entre a fantasia autista e a realidade sensorial. Finalmente, discutindo a satisfaşão oferecida pela arte, Pruyser encontra mais uma analogia com a religião, enquanto a satisfação produzida pela arte e pela religião é ambígua, correndo pelo contínuo do prazer e da dor. Facilmente se associam os efeitos estéticos à dimensão fascinante da religião, porém seu componente tremendo suscita reações sofridas, quais o temor, a culpa, a vergonha, o remorso, e de modo geral, o sentido do débito (Vergote, 1988, 1997), passíveis de expressão estética.

Vergote (1997), da Universidade de Leuven, e colaboradores seus, como J. Bachs (1991), através do ISAT/Images-Situations d'Apperception Thématique, estudaram a Natureza como possível mediação simbólica da presença de Deus. Fotografias da natureza alterada pelo homem não provocaram, em diplomados universitários catalães católicos do sexo masculino, experiência de profundidade nem referência religiosa. Ao contrário, fotos da descida do homem na lua e da escalada de montanhas obtiveram "correlação significativa entre a profundidade da experiência da natureza e sua significação religiosa" (Vergote, 1997, p.161). Notese, contudo, que o índice de fé religiosa influiu na percepção religiosa dos estímulos. Além da Natureza, Vergote e colaboradores, como De Pauw (1975, citado por Vergote, 1997), estudaram também o poder evocativo da experiência religiosa na música. A Paixão de S.Mateus, de Bach, e hinos ambrosianos foram percebidos, nessa ordem, pelos crentes e descrentes de sua amostra, como os mais religiosos e os mais belos; o Incarnatus, da Missa em dó menor de Mozart, o Requiem, de G. Ligetti, e a Última Ceia, de Jesus Cristo Superstar, não foram percebidos como música religiosa. J. Bachs, psicólogo da religião da Universidade Autônoma de Barcelona, recorda o poeta catalão J. Maragall, que escreve: "Se o mundo é tão belo, Senhor, quando o vejo com tua paz em meus olhos, que mais nos podes dar numa outra vida...?” É óbvio o préenquadramento religioso da percepção estética do poeta, mas assim mesmo ele parece sugerir uma continuidade íntima entre a beleza do mundo e a esperança religiosa, que não é nem a simples beleza nem a esperança (Bachs, 1996). 


\section{A Pesquisa}

Propusemo-nos explorar a questão da substituição da experiência religiosa pela experiência estética por meio de uma pesquisa empírica com artistas plásticos, discutida no âmbito conceitual e epistemológico. Distinguimos primeiramente, com Berger (1974), van der Lans (1986) e Vergote (1986), entre religião substantiva, denotada pela linguagem comum e referida ao sobrenatural (energias, espíritos, deuses, Deus), e religião funcional, entendida como qualquer realidade fundamental que dá sentido à vida, ao mal e à morte. Distinguimos, em segundo lugar, com Vergote $(1974,1997)$, entre o religioso, referido ao sobrenatural, e o sagrado, relativo aos valores essenciais e ideais. A partir dessas distinções, levantamos as hipóteses de que a experiência estética pode substituir a experiência religiosa no sentido funcional, mas não no sentido substantivo, e de que a experiência estética.pode ser uma experiência do sagrado.

Aproveitamos a peculiar circunstância da realização, de outubro a dezembro de 1996, da $23^{\text {a }}$ Bienal Internacional de São Paulo. O tema da $23^{a}$ Bienal era "A Desmaterialização da Arte no Final do Milênio", título que poderia ensejar a discussão da arte como imaterialidade, espiritualidade, sacralidade e religiosidade. A Exposição apresentava diversas sugestões desse encaminhamento. Na entrada do "Espaço Museológico", onde se expunham as obras de Picasso, Muench, Klee e Warhol, podia-se ler, de forma evanescente, em branco sobre cinza: "As coisas assim a gente mesmo não pega nem abarca. Cabem é no brilho da noite. Aragem do sagrado. Absolutas estrelas". O expositor chinês Qiu Shihua, cujas telas eram nuances de branco, explicava que "at the edge of visibility a view becomes a vision" e que sua intenção era "(to bring) the viewer back to the starting point at which sight begins to differentiate forms, and the mind constitutes a visual world", o que ele conseguia porque "he transforms both painting and vieweing into a spiritual exercise". Ao lado da escultura em fios do venezuelano Jesús Sota lia-se: "O imaterial é a realidade sensível do universo. A arte é o conhecimento sensível do imaterial". E na sala inteiramente dedicada a Mestre Didi (Deoscóredes Maximiliano dos Santos), o visitante é informado de que "Mestre Didi é sacerdote-escultor. Esculpe e executa objetos para os rituais, e é responsável pelo manejo dos materiais sagrados. Apreciar os trabalhos de Mestre Didi, à parte seu valor puro, implica recolocar e interpretar as obras-símbolo dentro do contexto mítico do qual surgiram para revelar o mistério litúrgico que carregam e localizar o sacerdote-artista como porta-voz, sensível coletor e original reformulador de uma cultura e de um povo". E Rubem Valentim explica, ao lado da obra, "procuro transformar em linguagem visual o mundo encantado, mágico e provavelmente místico que flui continuamente dentro de mim".

\section{Método}

\section{Participantes}

Participaram da pesquisa 8 destacados artistas plásticos, desenhistas, pintores e/ou escultores, 6 homens e 2 mulheres, com idade variando de 46 a 70 anos, escolhidos aleatoriamente de uma relação fornecida pelo Museu de Arte Contemporânea da Universidade de São Paulo. Conquanto 2 se declarassem, espontanemente, católicos e 2 outros interessados no Candomblé, nenhum dos artistas pôde ser considerado praticante regular de uma religião organizada.

\section{Instrumento}

O instrumento foi uma entrevista que compreendia dois tópicos, desdobrados em alguns itens: 1) O lugar da arte na vida pessoal do entrevistado (o artista como criador e como apreciador de arte; identificação com algum artista); 2) A relação percebida pelo entrevistado de sua atividade artística e da arte com o religioso, o sagrado, o espiritual em sua vida (algum deus presente/ausente na obra de arte do entrevistado; alguma relação -diferença, continuidade, substituição- percebida entre arte e religião; o tema da 'desmaterialização' da obra de arte e imaterialidade, espiritualidade, sagrado, religioso).

\section{Procedimento}

As entrevistas foram realizadas por quatro duplas de psicólogos pós-graduandos em Psicologia Social, e ocorreram na residência do artista ou em seu local de trabalho. Com a anuência dos entrevistados, o teor das entrevistas foi gravado e posteriormente transcrito. A análise qualitativa dos depoimentos considerou-os em seu valor de face e no plano consciente, e consistiu na identificação consensual dos temas experiência estética, experiência religiosa e experiência do sagrado nas falas dos entrevistados.

\section{Resultados}

Em relação ao primeiro tópico, obtivemos as informações seguintes. Em geral, os artistas atribuem ao ambiente familiar, escolar e social o encaminhamento para a arte. Admitem como necessária uma predisposição biológica para a atividade artística, que desencadeia algum tipo de comunicação, comparável à 'habilidade circense', mas não ainda a expressão de arte. Destacam, contudo, com muito maior ênfase, a aprendizagem. Assim, não existe inspiração ou criatividade que não seja trabalho, exercício, experimentação com o material, diálogo com a obra em andamento, observação atenta do ambiente, aprendizagem e prática de um código profissional específico. De passagem, negam que inspiração seja um estado de 'transtorno', ou algo parecido com 
'incorporação' ou 'baixa' de espíritos. Há quem reconheça na cultura espírita um ambiente propício para a utilização de certas habilidades, como as do pintor Gasparetto, mas nesse caso tratar-se-ia não de elaboração artística, mas de 'manifestação espiritual' por meio de habilidades já desenvolvidas pela pessoa. Um outro entrevistado, que ofereceu a descrição talvez mais complexa da criatividade (processo ininterrupto, que engloba idéia, tecnologia e materiais, em diálogo com a sociedade), concluiu a exposição com uma referência abrupta a Deus: 'o processo criativo, não sei, não posso imaginar o que seja, porque não acredito em Deus'.

A arte, como que fazer, ocupa lugar central na vida dos entrevistados. É 'alimento básico, obsessão', 'dedicação total', 'angústia pelo lugar no mundo', 'tentativa de entender o mundo, processo de auto-conhecimento', 'visão de mundo', 'esforço para melhorar o relacionamento humano e a qualidade de vida', 'preenchimento completo da pessoa', 'ligada à total função de viver, essência da elegância do viver na terra, substituto da terapia, prazer de viver', 'urgência, excitação, algo vital'.

Alguns artistas tiveram contato terapêutico com a psicanálise. Um deles confirma plenamente a posição de Freud de que o artista não necessita dela: 'a vantagem do artista é que ele está virado para fora; o psicanalista tem que cavoucar...; aqui (no trabalho do artista), está tudo do avesso... o inconsciente está do lado de fora'. Ouvimos o eco da experiência à citação do psicanalista: "os artistas têm uma saúde psíquica à prova de bala, porque conseguem viver perigosamente sem capotar" e "o louco entra no inconsciente e nunca mais sai; agora, o artista vive perigosamente: ele vai pegando coisas que estão abaixo do nível da consciência, na medida que você executa você traz isso para o nível do consciente".

Como se vê, os entrevistados foram explícitos no tocante à experiência da criação artística. Não deram relevo à experiência estética como receptores, a não ser em um caso, que insistiu na aprendizagem do olhar e no gosto proveniente da identificação com algum trabalho.

Os entrevistados coincidem em reconhecer a influência de algum artista e de alguma obra no início de suas carreiras. Coincidem também em dizer que, à medida que se vão firmando como artistas, sobretudo nesta época de pós-modernismo na arte, relativizam preferências por obra ou autor.

Em relação ao segundo tópico obtivemos as seguintes posições. Um dos entrevistados testemunha que 'a relação entre arte e religião vibra' dentro dele e afirma que se sente 'imbuído de Deus' e 'em comunhão extraordinária' com ele quando se põe a criar. Católico 'pré-conciliar', mas 'aquariano' voltado para o futuro, rejeita a imagem tradicional do Deus severo: Deus é alguém bem-humorado, bonachão, amigo, sem censura', ligado à vida e ao sexo, muito na linha do kitsch, que é a modalidade humorística da arte a que ele se tem dedicado. Considera a obra de arte um 'arremedo do Universo' e prefere à arte 'o esplendor da beleza deixada por Deus'.

Em geral os entrevistados excluem conscientemente qualquer presença de Deus em seu trabalho criativo, pois ou se declaram descrentes, ou não aceitam o Deus das religiões, ou não se sentem 'médium ou canal' 'incorporando' alguma entidade espiritual. Alguns se sentem perplexos com a aproximação entre arte e Deus, na qual nunca pensaram. Há quem admita que outros artistas possam incluir em seu trabalho a dimensão do sagrado e do religioso. Estão, porém, todos cientes da intersecção histórica entre religião, Igreja e arte no Ocidente, relação que perdura em sua própria atividade, cujo imaginário acolhe 'sem comprometimento' símbolos de todas as religiões. É possível, também, segundo alguns, que haja em seu trabalho uma presença de Deus inconsciente, que poderá ser eventualmente reconhecida pelo olhar de terceiros.

Um dos entrevistados afirma que a arte substitui a religião, como substitui também a terapia e a literatura. Para outro, não só a religião e a arte, mas também 'as drogas, a natureza, um belo cavalo, qualquer coisa pode levar ao êxtase'. Mas há quem pense que a arte está em crise porque 'não atende mais ao problema religioso no mundo' e quem fale na 'morte da arte'.

Várias são as afirmações de diferença entre religião e arte. Assim, a religião 'estabelece parâmetros de vida', enquanto a arte não o faz; a religião 'impõe limites', ao passo que a arte 'abre horizontes'; a religião coloca distância e a arte aproxima do respectivo objeto; 'a arte não ensina que devemos amar o próximo, mas através da arte podemos amar o próximo’. Além disso, a criação artística 'é emoção pura: não tem a ver com religiosidade'. 'O artista não se preocupa com o espiritual'. Talvez essas diferenças expliquem, 'por que a população miserável procura refúgio na religião e não, infelizmente, na arte' e, de outro lado, por que a arte pode servir de 'meio de clareza de viver' para pessoas com problemas.

Há também continuidades e analogias entre arte e religião. Uma como outra buscam algo de 'mais absoluto' e de 'menos material'. Há certa proporcionalidade entre ambas, que permite imaginar que 'o artista se coloca diante da arte como talvez as pessoas se colocam diante da religião'. 'Arte e religião passam pela abstração', abandonando o concreto imediato. Mais: 'existe uma identidade de disposição das pessoas com relação à arte e à religião'. O artista tem em relação ao objeto de arte 'reverência religiosa' e 'distanciamento'. O objeto de arte 'é sacralizado' porque tem valor como 'portador de uma verdade religiosa e sagrada', a 'verdade daquele artista'. Mas a verdade da arte não exige da sociedade distância e 
reverência, como a religião: 'a arte tem de fazer parte do mundo’. Para um dos entrevistados a auto-compreensão do artista como unidade individual num meio ecológico, à maneira da árvore que cresce idêntica à semente e se torna uma espécie da ecologia, é uma 'visão religiosa' na qual insiste, mas trata-se de uma religião 'mais sensorial e física do que espiritual'. Para ele, 'religião é uma sensação física de você dizer: que bonito, que agradável, como isso é verdadeiro!' Mas isso 'pára no mundo mesmo, não vai além'.

Há uma região nebulosa onde arte, religião e mística podem se embaralhar. Impressionado pela brevidade da vida, um entrevistado, agnóstico depois de uma educação católica repressiva, caracteriza como 'forma religiosa' o que descreve como 'o mistério das coisas, a metafísica da indagação sem foco, a consciência da brevidade da vida em comparação com a longevidade da arte, a metafísica do tempo, o sentirse tijolo numa construção com começo e fim'. Outro artista, que diz não se aprofundar, reconhece que 'na fronteira do desconhecido, entra tudo'; 'o desconhecido passa a virar coisa mística; quando chega aí, fica tudo muito solto para mim, já não consigo organizar mais, porque é o desconhecido’.

A experiência artística e o sagrado não se relacionam 'em hipótese alguma' para um dos entrevistados. O sagrado seria objeto de 'adoração, contemplação imóvel', quando ele, como artista, está voltado para a ação, a produção. Nunca aconteceu comigo nada que me oferecesse uma magia misteriosa sagrada, a não ser a minha própria independência'. Outro artista, que se diz ateu, declara que o sagrado é o pintor medieval Giotto, 'uma experiência maior, uma experiência espiritual'. Para um terceiro, a atividade artística não se relaciona com o sagrado, porque o sagrado está ligado à religião. Reconhece que o homem tem de viver com valores próprios, sem usar a religião 'como muleta'. O exercício da arte, em certos momentos, permite transcender o cotidiano e a condição animal do homem, mas o prazer que resulta desse transcender não sabe 'se é ligado ao sagrado, ou ao sensual, mesmo sexual até. De resto, os atributos tradicionais de Deus se encontram 'na obra' e 'no artista'.

O tema da "desmaterialização" permitiu várias associações. Há os que, atendo-se imediatamente à desmaterialização nas artes plásticas, explicam-na como 'o trabalho com materiais insólitos (sal, terra, lixo, plástico)', ou como 'o retorno ao fazer, o afastamento da técnica', ou como simples 'jogo de palavras', uma vez que nas artes plásticas 'há sempre o registro material'. Nessa última acepção, também o sagrado e o religioso 'se expressaram pela escultura e a pintura. O barroco, por exemplo, é a exorbitância, é a ópera religiosa'.

Outros, todavia, associam "desmaterialização" ao sagrado e ao religioso. Um entrevistado afirma categoricamente que a desmaterialização ‘tem’ algo a ver com o religioso, por ‘dar lugar ao vazio, onde o olhar do outro pode ver inclusive a Deus'. Um outro afirma que a "desmaterialização", 'antiarte que é arte', iniciada há décadas por Marcel Duchamp, 'é um raio x da violência no mundo' e tem clara 'conotação espiritual e religiosa' associada ao fim do milênio. Um terceiro admite, hesitante, que o tema pode abrir para o espiritual e que, no seu caso, o espectador que tivesse 'essa leitura' talvez pudesse ajudá-lo a descobrir o que ele mesmo tinha criado sem saber.

Outras associações tendem a relacionar arte e sagrado. Um dos entrevistados constata, a partir da 'sacralização' do objeto de arte nos museus, que o objeto 'acaba sendo sacralizado porque tende a ter um valor na sociedade': 'o objeto recebe da sociedade uma carga que permite dizer que a sociedade $o$ sacraliza'. Esse valor é expresso socialmente nas elevadas quantias pagas pelo objeto de arte. E acrescenta que seu traço artístico visa a ajudar as pessoas a abrir-se com harmonia e limpidez. Essa 'dedicação, abertura, receptividade e generosidade' que vive em seu trabalho corresponde a uma 'relação religiosa', que ela desconhece no sentido próprio.

\section{Discussão}

O teor das entrevistas manifesta claramente que os entrevistados não se alinham com Goethe. Parece que não existe neles a consciência de incompatibilidade, exclusão ou necessária opção entre religião e arte. Além disso, os entrevistados não parecem tampouco pertencer àquela elite cultural contemporânea para a qual apenas a arte preenche os anseios do espírito. É interessante, com efeito, notar que a substituição da religião pela ciência foi um desejo muito mais vigoroso e compartilhado no meio acadêmico do que o da substituição da religião pela arte. Um indício dessa diferença foi a ausência, praticamente total, de ressentimento anti-religioso, em contraste com o jorro de recriminações contra a Igreja Católica e contra Deus, encontrado em pesquisa com acadêmicos avançados (Paiva, 1994).

Uma segunda evidência é a de que os artistas têm muito maior clareza acerca de sua profissão do que acerca da relação entre experiência estética e experiência religiosa. Afirmativos acerca da profissão, são hesitantes acerca das relações entre religião e arte. Nota-se, por exemplo, consenso quanto à natureza da inspiração criadora, à necessidade de alguma habilidade natural, à aprendizagem do ver artístico, à freqüentação dos artistas como referências, ao progressivo abandono dos modelos, ao diálogo com a obra de arte em andamento, ao domínio dos materiais e das técnicas. Tal como aconteceu com os acadêmicos, os artistas são competentes em sua área profissional. 
Uma terceira verificação é a da preferência dos entrevistados por discorrer sobre o processo da criação, e não sobre a recepção da obra de arte. São apreciadores da arte, possuem coleções de objetos de arte ou de referências a esses objetos, mas consideramse produtores e não consumidores de arte. Às vezes expressam essa diferença dizendo caber à sociedade, enão ao artista, atribuir o caráter de arte ao produto, ou então, afirmando distância reverente em relação à obra por parte do artista, mas não por parte da sociedade.

Mais fundamental é o lugar ocupado pela arte na vida dos entrevistados: alimento, obsessão, dedicação, angústia, visão, esforço, completude, prazer vital, urgência. Em todo o caso, o papel declarado da arte sugere que se trata de um particular quadro de referência conceitual e valorativo por meio do qual os artistas se vêem. Mesmo as contingências de ordem cotidiana, como aquisição de material, supervisão de trabalhos por terceiros, relações com o marchand, encomendas de particulares ou de órgãos públicos, e até ataques pessoais, são elaboradas cognitivamente segundo as categorias da arte. Isso leva a pensar que os entrevistados percebem o mundo e agem sobre ele como objeto estético.

Os artistas entrevistados não ligam a inspiração criadora a alguma realidade religiosa. Quando admitem alguma mixagem entre arte e religião, como no caso do pintor espírita Gasparetto, fazem questão de distinguir o que (não) é arte e o que é religião. Excluem claramente o êxtase, o transtorno, a incorporação ou a baixa de realidade sobrenatural. A inspiração artística é claramente de caráter secular. Ainda assim, um deles, de cultura greco-ortodoxa, preferiu confessar sua ignorância do processo criativo, "porque não acredita em Deus". Essa referência intempestiva e deslocada a Deus faria pensar na sobrevivência da conceituação da arte como "entusiasmo" ou possesssão por um deus.

Frente ao segundo tópico, os entrevistados mostram-se ao mesmo tempo mais hesitantes, mais sutis e mais sugestivos. Um único entrevistado, que se declara espontaneamente católico, parece conjugar arte e religião de maneira consciente: sua preferência pelo kitsch, 'a gota de humor que falta na arte', modifica seu olhar sobre o Deus da infância e da adolescência, e lhe faz descobrir alguém bem-humorado e sem censura sexual. Além de rezar antes do trabalho e de pedir a Deus que sua obra colabore para o entendimento dos homens, esse artista se coloca no papel de aprendiz de Deus, fazendo arremedos da beleza deixada por Ele no Universo.

Mas esse é uma exceção. A relação entre arte e religião é negada por todos, com várias razões. O máximo que admitem é uma eventual presença inconsciente de Deus, que não é excluída tanto porque sabem que há mais na motivação humana que os motivos conscientes, quanto porque existem regiões de fronteira, de vida e de morte, onde as referências religiosas da infância, da família ou, em geral, da cultura reaparecem num horizonte provável. Os motivos religiosos, os símbolos de várias procedências religiosas, são utilizados sem compromisso, como do artista plástico indiano Anish Kapoor se diz que "convoca Kali, a Cabala, a Transfiguração e a Caaba" (Herkenhoff, 1996). De acordo com Arnheim (1987) não é necessário o comprometimento religioso para se lidar com símbolos religiosos que também são grandes temas humanos: caberá ao espectador interpretá-los religiosamente, experimentá-los estética e religiosamente, trazendo para isso a palavra de algum credo religioso. $\mathrm{O}$ entendimento de Arnheim é de que a obra de arte é uma obra aberta e que o sentido religioso é acrescentado à obra pelo esclarecimento de uma palavra. Sem essa palavra, a obra é arte, é humana e é emocionante, mas não tem nada a ver com religiosidade. Quando a palavra religiosa é acrescentada pelo espectador, a obra de arte expande seu universo de referência. Note-se que o mesmo pode ocorrer em sentido contrário, quando uma obra religiosa, como a Pietà ou o Moisés, ou a Catedral de Barcelona (Arnheim, 1991), esvaziados da palavra da fé, recolhem-se ao universo de referência artístico e, nessa qualidade, são capazes de emocionar profundamente o espectador. A experiência estética pode, pois, ensejar a experiência religiosa, mas não é necessário que o faça. Para que a sugestão conotativa de religiosidade se defina, parece necessária a indicação denotativa da palavra. Religião, como sistema simbólico, é sistema de referência (Vergote, 1997), mas não basta qualquer referência para introduzir no sistema.

Os resultados empíricos se deixam entender com a distinção conceitual e epistemológica entre religião substantiva e religião funcional (Berger, 1974; van der Lans, 1986; Vergote, 1986). Entendida substantivamente, isto é, no sentido denotativo que lhe confere socialmente a linguagem, a religião tem como objeto o sobrenatural. Entendida funcionalmente, isto é, segundo as funções que se crêem por ela asseguradas na vida individual e social, a religião equivale à realidade fundamental que confere sentido às grandes interrogações da existência, e pode identificar-se com a ciência, o empenho político, o prazer, o esporte.

Nesse âmbito conceitual e epistemológico inclui-se a discussão do sagrado. Com Vergote (1974;1997), distinguimos conceitualmente o sagrado não apenas do profano mas também do religioso, e definimos como sagradas "as realidades que representam valores essenciais e ideais, das quais o homem se vê beneficiário e garante", realidades "que comportam o interdito de transgressão, porque sua violação destruiria o próprio sentido de existência, solidário desses valores" (1974, p. 475), realidades percebidas como inerentes ao mundo e reveladoras de um mistério (Vergote, 
1997). Pesquisa realizada por Richard (1973, citado em Vergote, 1997), por meio do diferencial semântico, com os conceitos de "sagrado" e "Deus", revelou que "Deus" recebe conotação elevada por associações tanto de altura como de profundidade, ao passo que "sagrado" é associado elevadamente à dimensão de profundidade e muito menos à de altura. Exemplos de associações de profundidade são os itens seguintes: 'toca no que temos de mais pessoal, íntimo, secreto, toca no coração do sentimento, interioridade, revela ao homem seu valor único, invade todo o ser, é encontrado quando o homem entra em si, faz aceder à autenticidade, fonte e origem, dá seriedade e peso às coisas, fecundo, enraíza-se nas forças vitais, mistério'. Exemplos de associações de altura são as associações positivas com 'força, excesso, potência, soberano, majestoso, dominador, sublime, fascinante, glorioso, admirável'.

Nos entrevistados não parece haver confusão entre arte e religião tomados substantivamente. Em alguns há uma interrogação honesta quanto ao sentido definitivo da arte, da vida, da religião: 'na fronteira do desconhecido' pode despontar uma visão que dá conta das fragmentações da vida, o que um dos entrevistados denomina 'forma religiosa'.

Funcionalmente, há reconhecido paralelismo entre arte e religião. Ambas estão em busca de algo menos palpável, do absoluto; ambas provocam reverência; o produto da arte 'é portador de uma verdade religiosa e sagrada, a verdade do artista'; 'os atributos tradicionais de Deus se encontram no artista e na obra'. Paralelismo não implica, de imediato, substituição funcional. Porém para alguns, talvez incitados pela situação da entrevista (Bruner, 1990), essa substituição parece desejável: 'o artista se coloca diante da arte como talvez as pessoas se colocam diante da religião'; e com a ressalva de que sua religião é sensorial e física, um dos entrevistados insiste em que a visão da auto-compreensão do artista é 'religiosa'. A substituição de funções não oblitera, porém, a diversidade entre arte e religião enquanto, por exemplo, esta ensina e aquela não ensina, a religião impõe e a arte propõe. Também no que se refere à busca do absoluto, os entrevistados diferem no entendimento do menos material: para uns, a arte não-figurativa, a passagem pela abstração, seria a melhor analogia funcional entre arte e religião; para outros, sem a corporeidade da matéria não há como existir arte nem caminho para o absoluto. A cultura da familia parece, entretanto, orientar a opção pelo figurativo ou pelo abstrato na "busca" do absoluto: para o entrevistado de cultura judaica, o absoluto só pode vir pelo abstrato; para o entrevistado de cultura cristã, o absoluto vem por meio de formas materiais. Resquícios do "inominável” e da "encarnação"?

Aos entrevistados, no entanto, não parece bastar o papel vicário da religião assumido pela arte. Recordando as afirmações enfáticas dos entrevistados quanto ao lugar da arte em sua vida, 'visão de mundo', 'alimento básico', 'dedicação total', 'preenchimento completo da pessoa', e semelhantes, somos levados a aceitar em alguns casos uma aproximação entre experiência artística e sagrado. O entrevistado que afirma que arte e sagrado não se relacionam 'em hipótese alguma', e que para isso descreve as qualidades opostas de uma e outro, acrescenta sugestivamente que a única 'magia misteriosa sagrada' que lhe aconteceu foi sua própria 'independência'. Outro reconhece um caráter religioso na percepção da beleza, do prazer e da verdade da obra de arte. Ora, as expressões parecem indicar precisamente realidades "que representam valores essenciais e ideais, das quais o homem se vê beneficiário e garante", algo "inerente ao mundo", pois que 'a arte tem de fazer parte do mundo', mas "mistério manifestado" (Vergote, 1974, p. 475; 1997, p. 130), pois que o fundamenta no âmbito da verdade, do devotamento, da receptividade, da plenitude. Nessas expressões reconhecem-se as associações de profundidade que Richard (1973, citado por Vergote, 1997) encontrou para o sagrado, ao mesmo tempo que delas estão ausentes as associações religiosas de altura, reconhecíveis numa palavra de fé histórica.

As associações com a desmaterialização da obra de arte permitem vislumbrar outras conexões entre arte e sagrado, talvez entre arte e religião. Particularmente significativa é a afirmação da sacralização da obra de arte pela sociedade, que the atribui uma 'carga' valorativa, social e material, que exprime seu alto valor. A limpidez do traço, sua quase imaterialidade, dá forma à intenção 'religiosa' de ajudar as pessoas a 'abrir-se com harmonia e limpidez' para o mundo. A desmaterialização 'dá lugar ao vazio', morada do sagrado (Gonçalves Filho, 1996), e onde alguns, não o próprio entrevistado, podem 'ver inclusive a Deus'.

Alguns dos entrevistados, pois, não se contentam em separar arte e religião ou em viver o empenho da arte como outros vivem o empenho religioso, mas elevam o empenho artístico ao nível do sagrado. Dito de outro modo, entre os entrevistados encontraram-se todas as posições concernentes à relação entre experiência estética e experiência religiosa: arte como realização menor da prática religiosa; arte e religião como conceitos e práticas incompativeis; arte como substituindo a religião na busca do sentido e no encaminhamento das ações mundanas e sociais; arte revestida da densidade do sagrado. Ao mesmo tempo que se verifica uma distinção nítida entre religião e arte tomadas substantivamente na linguagem denotativa, verificase a transição do sentido conotativo da arte funcional para o da arte como sagrado. A arte adquire a função da religião principalmente para aqueles que a elevam ao âmbito do sagrado.

Resta a questão de como os artistas enveredaram pelos vários caminhos. Essa é uma questão pertinente da psicologia, 
embora requeira, para a resposta cabal, informação complementar e o concurso de outras disciplinas.

Note-se, em primeiro lugar, que, com uma exceção, os entrevistados gozaram de um clima favorável à arte no ambiente da família e da escola. A freqüentação da arte forneceu-lhes um quadro de referência cognitivo que lhes faz, como profissionais, encaixar boa parte de sua atividade no esquema artístico. Os entrevistados aludiram a esse enquadramento ao dizerem que a arte é visão de mundo e está ligada ao processo de entender o mundo e a si próprios.

Em segundo lugar, os entrevistados provêm de famílias favoráveis ou indiferentes à religião, porém não hostis a ela. Com uma exceção, os entrevistados demonstraram não fazer da religião um quadro de referência significativo, de modo que sua percepção do mundo não é religiosa, mas também não é anti-religiosa. Os interesses profissionais não colocam a religião no centro de suas ocupações e nem mesmo na periferia delas, mas a religião ou não chega a ser assimilada ao esquema cognitivo da arte ou é comandada perceptualmente pelo esquema. No primeiro caso, arte e religião se apresentam como domínios independentes; no segundo, a arte iluminará 'a busca do sentido e o encaminhamento das ações'.

O esquema cognitivo da arte adquire, porém, em alguns dos entrevistados, ressonâncias afetivas mais amplas que o acabam situando no nível do esquema cognitivo do sagrado. É possível que essa transposição se deva ao vácuo deixado, na vida de quase todos, pelo abandono da referência religiosa substantiva, presente na infância ao menos sob forma de identidade étnica. Alguns, com efeito, ecoam no uso das palavras a linguagem religiosa substantiva que os envolveu em épocas críticas do desenvolvimento e antecipam um possível reencontro das linhas soltas com que estão tecendo a trama da vida.

Pode ter havido, pois, para alguns dupla substituição do quadro de referência: do religioso pelo sagrado e também do artístico pelo sagrado. O olhar externo pode, no entanto, enxergar substituição de esquema cognitivo onde, subjetivamente, a substituição não ocorreu por falta de esquema prévio. Por isso é difícil falar com segurança em substituição funcional da religião pela arte ou pelo sagrado. Se nos satisfizer a consideração externa, o lugar que a arte acabou ocupando na percepção dos entrevistados justifica falar de um quadro de referência artístico; as características de profundidade que a arte adquiriu em alguns justificam falar de um quadro de referência sagrado. Nessa hipótese pode-se falar de substituição da religião pela arte ou pelo sagrado.

De resto, parece-nos que, conceitualmente, um quadro de referência perceptual poderoso não elimina outros quadros de referência comparáveis. Assim, um esquema cognitivo artístico ou sagrado pode compor-se com um esquema cognitivo religioso substantivo, não devendo necessariamente substituí-lo.

A construção de esquemas abrangentes ou unificadores depende, com efeito, da exposição da pessoa a estímulos físicos e sociais, com destaque da linguagem: as linguagens religiosas, sagradas e artísticas a introduzirão a percepções distintas, que o diálogo intrassubjetivo e intersubjetivo tornará compatíveis ou mutuamente exclusivas.

\section{Referências}

Allport,G. W. (1950). The individual and his religion. New York, NY: Macmillan. Allport, G. W.(1966). Personalidade: Padrões e desenvolvimento (D. M. Leite,Trad.). São Paulo: Herder/Edusp (Original publicado em 1961)

Allport,G. W.,Vernon,P. E. \& Lindzey,G. (1960). A study of values. Boston, MA: Houghton Mifflin.

Arnheim, R. (1987). Aesthetics: Visual aesthetics. Em M. Eliade (Org.), The Encyclopaedia of Religion. (Vol.1, pp. 47-51). New York, NY: Macmillan.

Arnheim, R. (1991). Beyond the double truth. New Ideas in Psychology, 9, 1-8.

Bachs, J. (1991). Belief, unbelief and religious experience (5 $5^{\text {th }}$ Symposium for Psychology of Religion, KUL, Leuven, 1991, Program Proceedings, 1-11.

Bachs, J. (1996). Aesthetic and religious experience in poetry $\left(7^{\text {th }}\right.$ Symposium for Psychology of Religion. Bellaterra/Catalunya. Abstracts, 28.

Baillache,G. (1993). L'écriture, l'expérience. Essai sur la littérature contemporaine. Etudes, fév (n.3782), 231-239.

Berlyne, D. E. (1980). Psychological aesthetics. Em H. C. Triandis \& W. Lonner (Orgs.), Handbook of Cross-Cultural Psychology (Vol.2, pp. 323-361). Boston, MA: Allyn \& Bacon.

Berger, P. L. (1974). Some second thoughts on substantive versus functional definitions of religion. Journal for the Scientific Study of Religion, 13, 235-133.

Bruner, J. (1990) Acts of meaning. Cambridge, MA: Harvard University Press.

Certeau, M. de (1996) A invenção do cotidiano (E. F. Ferreira, Trad.). Petrópolis, RJ: Vozes. (Original publicado em1990)

Charru, P. (1996). La théologie sonore d'Olivier Messiaen. Etudes, juillet-août, (n.3851-2), 91-100.

Court, R. (1989). Baroque et modernité. Etudes, juillet-août (n.371/1-2), 51-65.

Dupré, L.(1981). Spiritual life in a secular age. Daedalus. Winter, 21-31.

Fisichella, R. (1994). Balthasar, Hans Urs von. (L. J. Baraúna, Trad). Em R. Latourelle \& R. Fisichella (Orgs.), Dicionário de Teologia Fundamental (pp. 100-104). Petrópolis, RJ: Vozes.

Freud, S. (1978). O Mal-estar na civilização (J. O. de Aguiar Azevedo, Trad). São Paulo: Abril. (Original publicado em 1930)

Gonçalves Filho, A.(1996). Obra é uma ponte entre visível e invisível. O Estado de S.Paulo, 14.9. Caderno D p.16.

Herkenhoff, P.(1996). Anish Kapoor faz o elogia da matéria. O Estado de S.Paulo, 11.8. Caderno D p.3.

Krech, D. \& Crutchfield, R. S. (1971). Elementos depsicologia. (D. M. Leite \& M. L. M. Leite, Trads). São Paulo: Pioneira. (Original publicado em 1958)

Montrond, H. de (1996). Parcours en art sacré. Etudes, mai, (n.3845), 665-673.

Otto, R. (1936). The idea of the holy (J. W. Harvey, Trad). Oxford: Oxford University Press. (Original publicado em1917)

Paiva, G. J. de (1994). Religious itineraries of academics: A psychological discussion. Em J. Corveleyn \& D. Hutsebaut (Orgs.), Belief and unbelief: psychological perspectives (pp. 137-154). Amsterdam/Atlanta: Rodopi.

Pruyser, P. W. (1968). A dynamic psychology of religion. New York: Harper \& Row.

Pruyser, P. W. (1976). Lessons from art theory for the psychology of religion. Journal for the Scientific Study of Religion, 15, 1-14. 
Rehfeld, W. I. (1981). Considerações sobre a ocorrência de estruturas de consciência religiosa em filosofia. São Paulo: Universidade de São Paulo, Departamento de Lingüística e Línguas Orientais. Boletim,34, 3-303.

van der Lans, J. (1986). Two opposed viewpoints concerning the object of the psychology of religion. Introduction. Em J.A.van Belzen \& J.M.van der Lans (Orgs.), Current issues in the psychology of religion (pp. 76-81). Amsterdam: Rodopi.

Vergote, A. (1974). Equivoques et articulation du sacré. Em E. Castelli (Org.), Archivio di filosofia (pp. 371-492). Roma: Istituto di Studi Filosofici.

Vergote, A. (1986). Two opposed viewpoints concerning the object of the psychology of religion. Introduction. Em J. A. van Belzen \& J. M. van der Lans (Orgs.), Current issues in the psychology of religion (pp. 67-75). Amsterdam: Rodopi.

Vergote, A. (1988). Guilt \& Desire. Religious attitudes ant their pathological derivatives (M. H.Wood, Trad.). New Haven/London: Yale University Press. (Original publicado em 1978)

Vergote, A. (1997). Religion, Belief and Unbelief. A psychological study. Amsterdam/ Atlanta: Rodopi. (Original publicado em 1983)
Watts, F. \& Williams, M. (1988). The psychology of religious knowing. Cambridge: Cambridge University Press.

Weber, M. (1982), A ciência como vocação. Em H. H.Gerth \& C. W. Mills (Orgs), Ensaios de sociologia (pp. 154-183). (W. Dutra, Trad). Rio de Janeiro: Zahar. (Original publicado em1946)

Whaling, F. (1985) The study of religion in a global context. Em F. Whaling (Org.), Contemporary approaches to the study of religion (Vol. I, pp. 391-443). Berlin: Mouton.
Recebido:26/05/2003

Última revisão: $28 / 08 / 2003$

Aceite Final: 23/09/2003

Sobre o autor

Geraldo José de Paiva é Livre-Docente e Professor Associado do Instituto de Psicologia da Universidade de São Paulo, com pós-doutorado em Psicologia da Religião na Universidade Católica de Louvain-la-Neuve (Bélgica), Coordenador do GT Psicologia \& Religião, da ANPEPP, Coordenador do Grupo de Pesquisa do CNPq Psicologia Social da Religião e Coordenador do Programa de Pós-Graduação em Psicologia Social do Instituto de Psicologia da USP. 